\title{
FACTORY IMPROVEMENT PROGRAMS BREAKING THE IMPASSE
}

\author{
Roy Henderson \\ IMED \\ 9775 Businesspark Avenue \\ San Diego, CA
}

\begin{abstract}
The conversion of a medical equipment manufacturer's factory created an internal management impasse cons srning the selection of the most appropriate factory design. Simulated comparison of competing designs utilizing $\mathrm{PC}$ based simulation software was used for management decision comparison. The study focuses on the objective comparison of measurement criteria. The simulations were designed to quantitatively isolate each of the measurement criteria.
\end{abstract}

\section{FACTORY IMPROVEMENT PROGRAMS BREAKING THE IMPASSE}

Changing the organization of a factory often involves more change to the human factors than to the physical facility. A recent experience of IMED Corporation, manufacturer of intravenous feeding pumps for hospital use, graphically exemplified this dilemma during a program to convert the factory toward JIT principles.

The production organization at IMED had not been changed for over five years. The system was labeled a flexible manufacturing system (FMS) at the time.

The key features of this system were:

1. Independent free standing workstations where each worker assembled the delivered material at a rate independent from any other worker.

2. Conveyorized material transport to any of approximately 100 independent workstations through a series of conveyors and mechanical diverter arms.

3. Mechanized Work-In-Process material storage for kits waiting for a particular operation while all

workers that perform that operation are occupied.
4. The packaging of material for assembly into "kits". Each kit contained enough material to keep the independent worker occupied for $1-3$ hours.

5. A computerized control and information system connected to the conveyor system that tracked the following:

(A) The workstation or storage location of each kit of material.

(B) The status of each workstation: the operations its capable of, whether it can accept more material, how long it's been waiting for material.

(C) The sequenced routing that each "kit" type must follow for the correct assembly and test.

The FMS system design was driven by two principle factors: (1) The ability to change product mix quickly, (2) The ability to keep the labor force utilized during changing circumstances.

This flexibility came at a price. This price included the following considerations:

(1) The management attention required to maintain the daily organization of the production floor was more than desired.

(2) The material handling and administration connected with the "Kitting" process added undesired costs.

(3) The total build time from material release to product shipment referred to as "Cycle Time" was very long (15-20 days for a product with 10 hours of actual labor content).

(4) Supplying tools and fixtures for the production area was complex and expensive. Since most any worker could perform most any operation, there 
was considerable duplication and under utilization of tools and fixtures.

IMED's manufacturing management began exploring different production organization ideas in 1991.

The objectives IMED wanted satisfied, if a major change to the factory organization was to take place were:

(1) Reduction in "Cycle Time".

Purchased material comprises over $50 \%$ of the product cost. Long "Cycle Times" drive up the amount of inventory required to support the factory.

(2) Reduced assembly mistakes and simplification of the repair activities.

(3) Reduction in overhead. Currently an excessive amount of administration is required to keep the factory organized and supplied with material. The new system must have a simple way of dealing with material supply issues.

(4) Simplification of material handling logistics.

The FMS system controls, both hardware and software, were very complex. They were becoming obsolete and replacing the system with another of equal complexity would be very expensive. The new material handling system should have a much simpler control system.

(5) Improvements in direct labor efficiency.

Although this was one of the objectives, its importance was secondary to the other factors. Since much of the product content was in the form of purchased components and fabricated parts, the direct labor content within IMED's factory was a small portion of total cost. Improvements in labor utilization, training, and supervision were more important than pure efficiency.

The concepts of JIT (Just-in-Time) production seemed to fit the desires of IMED's management. A number of in-house seminars were conducted, lead by outside consultants, to further educate the IMED

management and administrative staff in the principles of JIT. During these seminars some tell tale signs began to emerge revealing the fact that making serious changes to IMED's factory may be difficult within the existing management structure.

\section{IMPASSE DEVELOPMENT}

The proposals for change presented by the manufacturing engineering department, designed to satisfy the objectives outlined above, met stiff resistance from the production management organization. The resistance centered on their desire to retain all the flexibility the present FMS system offered.

A pilot line proposal was developed and an agreement to implement on about $15 \%$ of the total production volume was reached.

The purpose of the pilot was to establish the measurement criteria and obtain actual performance data to help determine the best organization for factory wide implementation.

The pilot line was implemented with the plan to measure the following criteria:

Production output quantities:

Number of units outputted per unit of time.

Resource Utilizations:

Percent of time a worker or equipment is utilized for productive activity.

Direct Labor Time:

Total amount of labor used to produce one unit.

Repair Activity:

Percent of units requiring repair.

Material Handling Activity:

Number of times a material container must be handled per unit completed.

Total Cycle Time:

Total time a unit is in the manufacturing system (from material issuance to shipment). 
Average Inventory Levels:

Average inventory in the system including WIP (Work in Process).

Production Recovery time:

The amount of time to return to an "On Schedule" position after an unavoidable production stoppage.

The key features of the pilot line were:

1.Delivery of materials directly to the using workstation on the production floor. This eliminates the need for kitting of the parts.

2. Balanced progressive assembly of the product by a small five person assembly team. This assembly method made the direct delivery of material feasible.

3. Testing operations balanced into the assembly progression, eliminating the need to route the product to a separate queue and workstation for testing.

After several months of the pilot line operation data became available on several of the above criteria. Production management remained unconvinced, however, of the advisability of extending the pilot line organization factory wide.

At this point it was decided to utilize the capabilities of computer simulation to compare the measurable quantities of each of the competing production systems. The simulation was designed to utilize both theoretical and historical data. The historical data came from the JIT pilot line and the FMS assembly areas.

The simulation addressed each of measurable quantities in the following manner:

Production output quantities:

The production quantity output was determined by the operation time at each of the routing sequence steps. A material arrival schedule was set to keep all operations supplied.

\section{Resource Utilizations:}

The resources tracked werc the assembly workers, test equipment, and material handling operators. A material handling index was devised (number of totes handled to complete one finished unit) to compare the amount of material handling activity between the two production systems.

\section{Direct Labor Time:}

This is the total of all operation times with the extra labor for repair and retest added.

Repair Activity:

As mentioned above in the direct labor time, section the repair activity was driven by the probability for failure at each of the test operations. A time for repair and retest was added to the total labor time required to complete a unit.

Material Handling Activity:

This is the number of totes of material that must be handled to complete one finished unit. Additionally, the amount of labor required to refill and handle the material totes was also identified in the simulation. Total Cycle Time:

This is a measure of the total time WIP inventory resides in the system. This was a very critical comparison between the two production systems. A decrease in cycle time quickly produces large savings in the investment in WIP inventory. The total cycle time was controlled in the simulation by setting the queue sizes, material handling time, and repair time to values that reflected the actualities of each production system.

Average Inventory Levels:

Inventory levels are a pure function of cycle time.

Production Recovery time:

This comparison is the measure of how quickly the production rate can be changed or the labor force re deployed to other products as a contingency against part shortages or other production stoppages.

This was a difficult issue to grapple with in the simulation. It involved probabilistic future events with both very uncertain occurrence and duration factors. 


\section{SIMULATION RESULTS}

The simulation incorporated features to address each of the measured areas separately. This allowed a comparison display to be prepared for each. These charts and graphs are included. The results of each of the measured areas is described below. Production Output:

The required production output was assured in both of the models. Although the resources necessary to meet the production requirements varied among the different options, the models were deliberately constructed to show that the production schedule could be met with any of the systems.

It is the comparison of the necessary resources under each of the options that this study really focused on.

\section{Resource Utilizations:}

The resource utilization charts illustrate how intensely each of the operation steps are utilized to meet the scheduled production rate.

Again the amount of resources were calculated to assure that the production schedules were met. What is revealing upon examination of the charts is the Progressive Assembly option results in utilizations that are more evenly distributed over all workstations. This is due to the fact that the work assigned to each assembler in the progressive assembly option is carefully designed through line balancing techniques. This combined with a constant daily production goal, results in steadier resource utilization.

\section{Direct Labor Time:}

Although one of the original goals of changing IMED's factory organization was not a reduction in the direct labor requirement. experience demonstrated there was a decrease in labor time under the progressive assembly option. The decrease is about $20 \%$.

Some of the reasons for the decrease are: (1) Defined daily output goal, (2) Better workstation organization, (3) The effect of working in a team environment and not wanting to be the one slowing the team' efforts.

Repair Activity:
This is an indicator of the number of assembly mistakes and overall quality under each of the production options.

It was clear that the progressive assembly option produces a marked improvement in quality. This is due to the much faster feedback to each assembler about any assembly mistakes or the use of defective material.

Material Handling Activity:

The material delivery system at IMED is a conveyorized transport system with a delivery point at each of the product and subassembly areas. An effective indicator of the material handling workload is the number of totes that must be handled for each unit completed.

The Progressive Assembly option results in fewer totes handled. About four per unit compared to five and a half for the FMS system.

Total Cycle Time:

It is in this area of comparison where the results are very dramatic and produce serious financial benefits. The total product build cycle time under the Progressive Assembly option is one fourth of the time required under the FMS system.

This translates into a enormous WIP inventory reduction and the working capital associated with the extra WIP.

Production Recovery Time:

It was the debate over this point that created much of the decision impasse.

IMED's definition of Production Recovery Time is: The amount of lost production time resulting from interruptions to the normal production activity. These interruptions can come from late delivery of material, defective material, breakdowns in production or test equipment, or product design driven problems.

The way this issue was handled in the simulation was to artificially stop production on a particular product for a ten day period. There was no attempt 
to simulate the detailed cause of the stoppage or the corrective action required. Production was simply stopped and then the amount of time required to recover the normal production quantities was tracked. Not surprisingly, the FMS method of production organization recovered quicker. This was because the FMS method was able to re deploy a greater amount of resources to the product behind schedule. It is area. schedule and labor use flexibility, that the FMS system has its advantage. However, all other areas of measurement are sacrificed for this one advantage.

\section{OVERALL CONCLUSIONS}

The use of simulation in this application was the critical factor that broke the managerial impasse preventing this factory reorganization from proceeding. The progressive assembly option was chosen. The simulation results convinced even what had been the most skeptical members of management.

Several phenomenons occurred during the study and simulation of this project:

(1)It forced all parties involved to think through all the relevant data required for the simulations. It was discovered that the reason for much of the disagreement on the best course of action was a narrow perspective from some individuals. The simulation forced everyone to take a more global view of the entire situation.

(2) Everyone involved had a better mental picture of what the final factory arrangement would consist of. Some people have the ability to construct an accurate concept from a verbal and pictorial presentation, others do not. The dynamic aspects of the simulation animation helped fill in the gaps necessary to provide a full understanding.

(3) The simulation acted as a "Scoreboard" on which alternative ideas could be measured. Rather than arguing over the merits of different factory design concepts on an abstract level, the key attributes were entered into the simulation and objectively compared.

The concluding thoughts of everyone connected with the project was the use of simulation was the technique that allowed the arrival at both the best factory organization and the consensus decision that allowed the project to proceed.

\section{REFERENCES}

ProModel PC User Manual, Version 5.0, ProModel Corporation, 1991

Deming, W. Edwards. Out of the Crisis

Massachusetts Institute of Technology Center for Advanced Engineering Study, 1982

Henderson, Roy and Kiran, Ali, "Kitting Elimination Supports Just-In-Time Principles" Industrial Engineering, March 1993, pp. $46-48$

\section{AUTHOR'S BIOGRAPHY}

Mr. Roy Henderson, Manufacturing Engineering Manager at IMED Corporation, received his B.S. in Industrial Management from California State University, Fullerton. He has extensive background in designing manufacturing and test systems for high technology product companies. During the past several years he has used computer simulation to help with both the design and acceptance of changes in operations. Previous uses of simulation at IMED Corporation include optimal test system planning, circuit board assembly equipment utilization and cost effectiveness of part traceability record keeping. 